\title{
Anti-Double Stranded DNA IgG Measurement
}

National Cancer Institute

\section{Source}

National Cancer Institute. Anti-Double Stranded DNA IgG Measurement. NCI Thesaurus. Code C154769.

The determination of the amount of anti-double stranded DNA IgG antibodies present in a sample. 